\title{
Methane hydrate formation in partially water-saturated Ottawa sand
}

\author{
W.F. WAITE,* W.J. WINTERS, AND D.H. MASON
}

\author{
U.S. Geological Survey, 384 Woods Hole Road, Woods Hole, Massachusetts 02543, U.S.A.
}

\begin{abstract}
Bulk properties of gas hydrate-bearing sediment strongly depend on whether hydrate forms primarily in the pore fluid, becomes a load-bearing member of the sediment matrix, or cements sediment grains. Our compressional wave speed measurements through partially water-saturated, methane hydrate-bearing Ottawa sands suggest hydrate surrounds and cements sediment grains. The three Ottawa sand packs tested in the Gas Hydrate And Sediment Test Laboratory Instrument (GHASTLI) contain $38(1) \%$ porosity, initially with distilled water saturating 58,31 , and $16 \%$ of that pore space, respectively. From the volume of methane gas produced during hydrate dissociation, we calculated the hydrate concentration in the pore space to be 70,37 , and $20 \%$ respectively. Based on these hydrate concentrations and our measured compressional wave speeds, we used a rock physics model to differentiate between potential pore-space hydrate distributions. Model results suggest methane hydrate cements unconsolidated sediment when forming in systems containing an abundant gas phase.
\end{abstract}

\section{INTRODUCTION}

Methane gas hydrate, a crystalline material in which individual methane molecules are held in cages formed by a hydrogen-bonded structure of water molecules, forms naturally in permafrost and continental margin sediments worldwide (Kvenvolden and Lorenson 2001). Global estimates suggest these natural hydrate systems store twice the carbon found in fossil fuel reserves and 3000 times the methane present in the modern atmosphere (Kvenvolden 1993a). Such large volumes have prompted gas hydrate to be considered a potential energy resource (Kvenvolden 1993b), a geohazard (Hovland and Gudmestad 2001; Sloan 1998), and a climate change agent (Kennett et al. 2003). Quantifying where and how much hydrate exists is crucial for seafloor stability assessments (Kvenvolden 1993a), for evaluating the permeability and thermal transport properties used in methane or petroleum recovery schemes (Kvenvolden 1993a; McGee and Woolsey 2000; Ruppel 2000), and for resolving the impact of methane hydrate in climatic change (Haq 2000).

Remotely estimating hydrate saturations in the natural environment requires accurate seismic velocity information for hydrate-bearing sediments (Hornbach et al. 2003). Seismic velocities depend on the bulk elastic moduli of the system, which are controlled by the grain-scale arrangements of hydrate and sediment. Dvorkin et al. (2000), considered four pore-scale hydrate distributions (Fig. 1): (1) hydrate floating in the pore fluid, (2) hydrate as a load-bearing member of the solid phase, (3) hydrate cementing grain contacts and evenly coating grains, and (4) hydrate acting as a cement and forming only at grain contacts.

For a given hydrate saturation, hydrate floating in pore fluid increases the seismic velocity primarily by increasing the moduli of the pore fluid and has the smallest impact on the host

E-mail:wwaite@usgs.gov sediment's elastic properties of the four distributions illustrated in Figure 1 (Dvorkin et al. 2000). Hydrate forming only at the grain contacts and acting as cement has the greatest impact on elastic properties, increasing the seismic velocity by locking individual grains together. This distribution dramatically increases the moduli of unconsolidated sediment even with a hydrate saturation of only a few percent (Helgerud 2001). Within a hydrate lens at Blake Ridge, the potential hydrate saturation has been estimated to range between 13 and $22 \%$ by modeling hydrate as contact cement and then as part of the pore fluid (Hornbach et al. 2003). The saturation estimate cannot be more tightly constrained without choosing a particular hydrate distribution.

Laboratory hydrate formation studies provide a means of judging which hydrate distribution model is appropriate for a given geologic environment. Tohidi et al. (2001) showed that methane hydrate forms primarily in the center of pores in waterrich systems initially containing discrete units (bubbles) of gas. Stern et al. (2000) and Waite et al. (2002) showed that hydrate cements sediment grains in gas-rich systems initially containing ice grains, which are effectively discrete units of water. Bridging these two end-member cases, we present a set of experiments utilizing the U.S. Geological Survey's GHASTLI (Gas Hydrate And Sediment Test Laboratory Instrument) facility to study unconsolidated, partially water-saturated Ottawa sand samples containing an interconnected methane gas phase. The abundance of gas in our samples is an analog for natural gas-rich systems such as may occur when gas recycles into an upward-migrating base of hydrate stability, as inferred by some for the Cascadia margin (Yuan et al. 1999) and Blake Ridge (Guerin et al. 1999).

A description of GHASTLI and its capabilities can be found in Winters et al. (2000). A detailed description of the sample construction and experimental methods used in this work are given in Winters et al. (this volume). Here we restricted our procedural discussion to items directly applicable to the modeling analysis. 


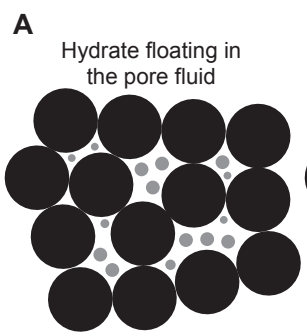

\section{B} Hydrate as part of the loadbearing granular frame

C Hydrate surrounding and cementing grains

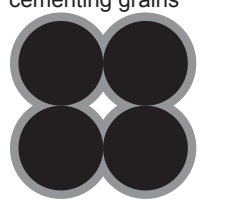

D
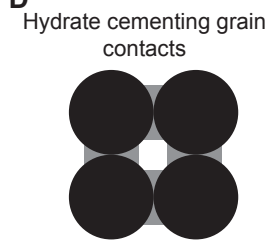

FIGURE 1. Pore-scale distributions of gas hydrate (gray) and sediment grains (black), from Dvorkin et al. (2000). The seismic velocity increase imparted by a given hydrate saturation in granular material grew in order from a to $\mathbf{d}$.

\section{EXPERIMENTAL PROCEDURES}

\section{Sample composition}

We studied methane hydrate formation behavior in three samples of Ottawa sand, partially water-saturated and containing an interconnected methane $\left(\mathrm{CH}_{4}\right)$ gas phase (Table 1). Each sample was approximately $14 \mathrm{~cm}$ high and $7 \mathrm{~cm}$ in diameter. Sample porosities approached $36 \%$, the porosity of an ideal random sphere pack (Mavko et al. 1998), a consequence of pouring the wet quartz sand during sample construction. Water saturation levels were chosen to cover a broad range while maintaining a continuous gas phase. We assumed that the water was homogeneously distributed because post-experiment water content measurements showed that the water saturation from top to bottom within a sample varied by less than $1 \%$.

To synthesize methane hydrate, the pore pressure within the sample was raised to $12 \mathrm{MPa}$, and the sample temperature was lowered to $279 \mathrm{~K}$ from room temperature. Pore pressure was held at $12 \mathrm{MPa}$ with a methane-filled syringe pump, which provided additional gas to replace methane used in hydrate formation. The samples were held at these conditions until the measured compressional wave speed stabilized (Fig. 2d). Though the sample temperature reached $279 \mathrm{~K}$ in less than 12 hours, the wave speed stabilization required approximately 1400,250 , and 220 hours for initial water saturations of 58, 31, and 16\%, respectively. Hydrate formation took place primarily while the sample temperature was stable, and we assume that the growth morphology was not significantly affected by temperature gradients present in the sample during cooling.

The hydrate volume formed in this procedure can be calculated either from the methane gas volume taken up during hydrate synthesis, or evolved during hydrate dissociation. Because synthesis lasted hundreds of hours compared to approximately 12 hours for dissociation, gas volume measurements during dissociation are less prone to errors from leaks in the system. To dissociate a sample, we raised the sample temperature through $288 \mathrm{~K}$ at $12 \mathrm{MPa}$ pore pressure. The volume increase associate with the transition from $\mathrm{CH}_{4}$ hydrate to $\mathrm{CH}_{4}$ gas $+\mathrm{H}_{2} \mathrm{O}$ pushed methane gas and water out of the sample chamber and into a collector. A syringe pump measured gas and water volumes entering the collector during dissociation. Several potential contributions to the collector volume change must be accounted for before the methane volume stored as hydrate can be calculated: (1) pore volume changes associated with sample deformation during dissociation, which was monitored by a syringe pump controlling the confining fluid pressure and can be accounted for directly; (2) thermal expansion of methane gas as the sample warms through the dissociation temperature; and (3) the volume change due to solid methane hydrate dissociating to gaseous methane and liquid water.

The collector volume change caused by thermal expansion of pore gas depends on the total pore gas volume. Without a priori knowledge of the hydrate volume in the pore space, we bound our estimate using the largest and smallest pore gas volumes for each sample, assuming all $\mathrm{H}_{2} \mathrm{O}$ in the system exists as either liquid water or hydrate. The largest pore-space gas volume occurs if none of the initial water converts to hydrate, in which case the gas volume is the same as its initial

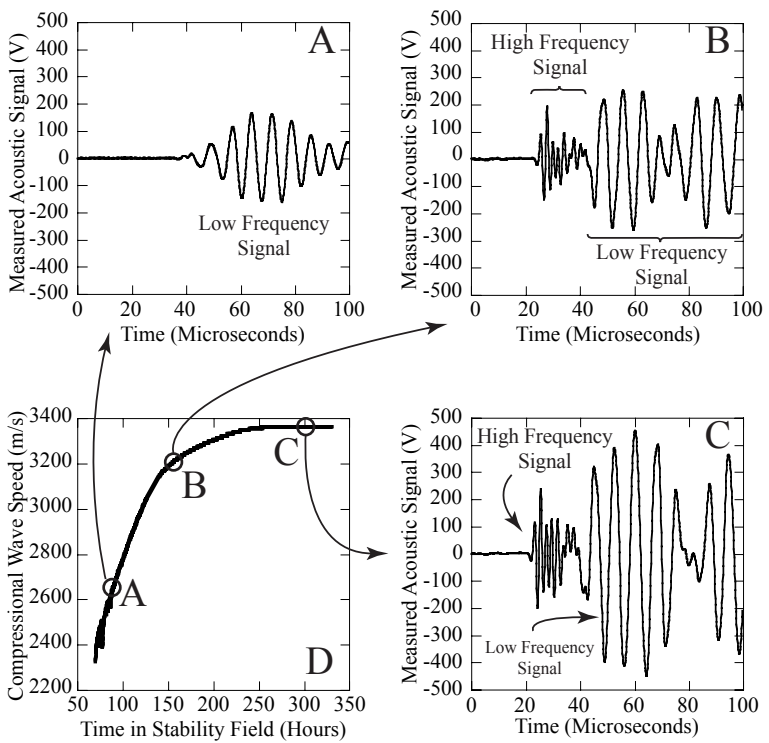

FIGURE 2. Waveform evolution in GH084. Hydrate formation in the quartz sand pack cements sand grains, increasing the measured wave speed as the synthesis ran to completion (d). Cementation stiffens the sample, passing first the low-frequency portion of the acoustic signal (a), then the high-frequency component (b). Both components then increased in amplitude until hydrate synthesis was complete (c).

TABLE 1. Initial sample compositions (by volume)

\begin{tabular}{lccccc}
\hline Sample & $\begin{array}{c}\text { Quartz } \\
(\%)\end{array}$ & $\begin{array}{c}\text { Water } \\
(\%)\end{array}$ & $\begin{array}{c}\mathrm{CH}_{4} \text { Gas } \\
(\%)\end{array}$ & $\begin{array}{c}\text { Porosity } \\
(\%)\end{array}$ & $\begin{array}{c}\text { Water Saturation } \\
\text { (\% of pore space) }\end{array}$ \\
\hline GH083 & 63.1 & 21.6 & 15.3 & 36.9 & 58 \\
GH084 & 60.6 & 12.4 & 27.0 & 39.4 & 31 \\
GH085 & 61.9 & 6.2 & 31.9 & 37.9 & 16 \\
\hline
\end{tabular}

Note: Average quartz grain size is $0.37 \mathrm{~mm}$, all uncertainties are $\pm 0.1 \%$.

value. The smallest pore-space gas volume occurs if all the water converts to hydrate, reducing the gas-filled pore volume accordingly. Based on these limits, we used the equation of state for methane (Sychev et al. 1987) to calculate the thermal expansion of pore-space methane as the sample warmed through the dissociation temperature. The effect was 3.4(2)\% of the evolved gas volume for GH085, which has the largest pore-space gas volume and smallest hydrate volume. The effect in GH084 and GH083 was $1.6(1) \%$ and $0.5(1) \%$ respectively. We subtracted this pore-gas thermal expansion volume from the volume increase measured during dissociation to obtain the volume change due to hydrate dissociation alone.

The total volume change due to methane hydrate dissociating to methane gas and liquid water is a combination of two volume changes: (1) a volume increase due to the release of methane, and (2) a volume decrease due to the hydrate structure collapsing to liquid water. The ratio, $n$, of $\mathrm{H}_{2} \mathrm{O}$ molecules to methane molecules determines how the total volume change is partitioned between these two contributions. Because hydrate is a non-stoichiometric solid, $n$ is variable and we were not able to uniquely determine the original hydrate volume from the total measured volume change. Instead we determined a range of possible hydrate volumes for each sample. The largest hydrate volume is obtained if the initial pore water completely converts to hydrate. The smallest volume is obtained if every molecular cage contains a gas molecule, meaning the cage occupancy is $100 \%$, and $n=5.75$. Using the average of these two end-member cases, with uncertainties covering the full range between the endmember estimates, we report the volumes of non-hydrate (Table 2) and hydrate phases (Table 3) in our three samples.

\section{Acoustic measurement}

Rigid sample endcaps, located at the top and bottom of the cylindrical sample, each housed a $1 \mathrm{MHz}$ compressional wave piezo-electric transducer. Compressional waves were produced in the top endcap, traveled down the sample's central axis, and were detected by the crystal in the bottom endcap. Wave speed was calculated by dividing the acoustic travel time through the sample by the sample length. We defined acoustic travel time as the first arrival of the signal, a downturn observ- 
TABLE 2. Sample composition after hydrate formation: non-hydrate phases

\begin{tabular}{lcccccc}
\hline & Density (g/cc) & Porosity (\%) & $\begin{array}{c}\text { Water } \\
\text { (\% of total volume) }\end{array}$ & $\begin{array}{c}\text { Water } \\
\text { (\% of pore volume) }\end{array}$ & $\begin{array}{c}\mathrm{CH}_{4} \text { Gas } \\
\text { (\% of total volume) }\end{array}$ & $\begin{array}{c}\mathrm{CH}_{4} \mathrm{Gas} \\
\text { (\% of pore volume) }\end{array}$ \\
\hline GH083 & $1.93(1)$ & $11(1)$ & $1(1)$ & $9(9)$ & $10.0(3)$ & $91(9)$ \\
GH084 & $1.77(1)$ & $25(1)$ & $0.9(9)$ & $3(3)$ & $24.0(3)$ & $97(3)$ \\
GH085 & $1.74(1)$ & $30.7(4)$ & $0.3(3)$ & $1(1)$ & $30.4(1)$ & $99(1)$ \\
\hline
\end{tabular}

Note: Quartz content same as in Table 1.

able in Figures $2 b$ and $c$. The wave speed, Figure 2d, is not reported until the first downturn can be resolved. A discussion of the first arrival's evolution is given in the results section. Based on travel time and sample length measurement uncertainties, we attribute $\mathrm{a} \pm 0.5 \%$ uncertainty to our reported wave speeds.

\section{HYDRATE DISTRIBUTION MODELS}

The predicted effect of hydrate formation on bulk and shear moduli in a partially saturated, unconsolidated sand can be estimated using the rock-physics approach of Dvorkin et al. (2000) and Helgerud (2001). Model predictions of the bulk modulus, $K$, and shear modulus, $G$, were combined with the sample density, $\rho$, to obtain the compressional wave speed, $V_{\mathrm{p}}$, using (Mavko et al. 1998):

$$
V_{\mathrm{p}}=\sqrt{\frac{K+\frac{4}{3} G}{\rho}}
$$

We calculated the density from our known sample composition (Table 2), but we relied on the rock-physics models to provide the bulk and shear moduli.

To predict $V_{\mathrm{p}}$, the density, bulk, and shear moduli of the dry sand frame were first calculated as a function of its porosity, mineralogy, and effective pressure using the methodology presented in Dvorkin et al. (1999). The effects of pore space gas and fluid on $\rho, K$, and $G$ were then calculated using Gassmann's (1951) equations. The effect of hydrate was then calculated for the four pore-scale distributions shown in Figure 1. Model predictions of $\rho, K$, and $G$ were used in Equation 1 to calculate $V_{\mathrm{p}}$, which can then be compared with our measured values to establish which grain-scale hydrate distribution provides the closest match. Using $\rho, K$, and $G$ and the Poisson's ratio, $v$, from Table 4 , model predictions are given in Table 5 for the dry and saturated sand pack as well as for each hydrate distribution for GH084, our midrange water-saturation sample.

The mathematical formalism for establishing elastic properties of the partially saturated, hydrate-free sand pack, referred to as the "baseline model," was described in Helgerud et al. (1999) and Collett (2001). Governing equations extending the baseline model to include the presence of hydrate are given in Dvorkin et al. (2000) and Helgerud (2001). Here we summarize the physical concepts involved in the modeling analysis.

\section{Baseline model}

The baseline model of Dvorkin et al. (1999) uses HertzMindlin (Mindlin 1949) contact theory to derive bulk and shear moduli of the dry sediment frame, which in our sample was a quartz sand pack. Three parameters are introduced in this theory: the effective pressure holding the sand pack together, the contact number describing the average number of contacts or supports for each grain, and the critical porosity (Nur et al. 1998) above which the sand pack is unable to support itself.
In our experiments, the effective pressure was held at 250 $\mathrm{kPa}$. The contact number, $C$, was calculated for each sample according to (Mavko et al. 1998):

$$
C=21.67-43.76 \varphi+25.98 \varphi^{2}
$$

using the porosity, $\varphi$, given in Table 1 . The critical porosity, $\varphi_{c}$, depends on the granular material, and based on tabulated results in Mavko et al. (1998), we estimated $\varphi_{\mathrm{c}}$ to be $40 \%$ for our samples.

For sample GH084, the predicted compressional wave speed through the dry frame was $895 \mathrm{~m} / \mathrm{s}$. We were not able to verify this prediction directly because a dry sand pack is too weak to pass a measurable compressional wave in the GHASTLI system. Because this prediction is only $27 \%$ of the measured wave speed of $3360 \mathrm{~m} / \mathrm{s}$ after hydrate formation, we conclude that the measured wave speed cannot be accounted for by effective pressure and the arrangement of quartz grains alone.

The effect of pore fluid was introduced via Gassmann's (1951) equations, in which the dry sand pack's bulk modulus was augmented by replacing void space having zero bulk modulus with pore fluid having a measurable bulk modulus. Fluid has no shear modulus, so the shear modulus of the fluid-saturated sand pack is identical to the shear modulus of the dry sand pack.

For the samples described here, the pore fluid was a mixture of water and methane gas. To account for the combined effect of pore space water and gas in the background model, Gassmann's equations were used to calculate the bulk modulus of a watersaturated sample, then a methane gas-saturated sample. For

TABLE 3. Sample composition after hydrate formation: hydrate phases

\begin{tabular}{lcccc}
\hline & $n$ & $\begin{array}{c}\text { Cage Occupancy } \\
(\%)\end{array}$ & $\begin{array}{c}\mathrm{CH}_{4} \text { Hydrate } \\
(\% \text { total volume) }\end{array}$ & $\begin{array}{r}\mathrm{CH}_{4} \text { Hydrate } \\
\text { (\% pore volume) }\end{array}$ \\
\hline GH083 & $6.00(25)$ & $96(4)$ & $26(1)$ & $70(3)$ \\
GH084 & $6.10(35)$ & $94(6)$ & $14.5(1.0)$ & $37(3)$ \\
GH085 & $6.00(25)$ & $96(4)$ & $7.4(4)$ & $19.4(1.0)$ \\
\hline
\end{tabular}

TABLE 4. Model inputs

\begin{tabular}{llccl}
\hline & $\rho(\mathrm{g} / \mathrm{cc})$ & $K(\mathrm{GPa})$ & $G(\mathrm{GPa})$ & \multicolumn{1}{c}{} \\
\hline Quartz & 2.65 & 36.6 & 45.0 & 0.06 \\
$\mathrm{CH}_{4}$ Hydrate & 0.926 & 8.70 & 3.55 & 0.314 \\
Water & 1 & 2.25 & 0 & 0.5 \\
$\mathrm{CH}_{4}$ Gas & 0.0108 & 0.021 & 0 & 0.5 \\
\hline
\end{tabular}

Notes: Quartz, water, $\mathrm{CH}_{4}$ gas data taken from Mavko et al. (1998). $\mathrm{CH}_{4}$ hydrate data from Helgerud (2001).

TABLE 5. Model predictions of compressional wave speed, $V_{p}$, Bulk modulus, $K$, and Shear modulus, $G$, for sample GH084, assuming a hydrate saturation of $70 \%$ (see Table 3 )

\begin{tabular}{lccc}
\hline & $V_{p}(\mathrm{~m} / \mathrm{s})$ & $K(\mathrm{GPa})$ & $G(\mathrm{GPa})$ \\
\hline Dry sand pack & 895 & 0.44 & 0.64 \\
Partially saturated sand pack & 1005 & 0.93 & 0.64 \\
Pore filling hydrate & 1080 & 1.2 & 0.64 \\
Load bearing hydrate & 1180 & 1.0 & 1.0 \\
Hydrate surrounding and cementing grains & 3370 & 7.6 & 9.4 \\
Hydrate as contact cement & 3865 & 10.3 & 12.1 \\
\hline
\end{tabular}


a homogeneous mixture of water and gas, these results were combined according to the relative water and gas saturations present in each sample. Once hydrate formed, however, there was little or no water left in the sample and rather than being homogeneously mixed, the gas and remaining water occupied different spaces within the pores. The bulk modulus of this water and gas mixture is given by combining the Gassmann results for the water-saturated and gas-saturated cases according to the "patchy saturation model" (Dvorkin and Nur 1998).

For sample GH084, the predicted compressional wave speed of the gas and water-saturated sand pack was $1005 \mathrm{~m} / \mathrm{s}$. As with the dry sand pack, this partially saturated sand pack did not pass a compressional wave in GHASTLI. We used GHASTLI to acquire compressional wave signals through a fully watersaturated version of the Ottawa sand samples described here, and the measured wave speed of $1880(30) \mathrm{m} / \mathrm{s}$ is in close agreement with the predicted wave speed of $1913 \mathrm{~m} / \mathrm{s}$.

\section{Hydrate in the pore fluid}

This model distribution assumes hydrate forming in the pore volume has no contact with solid quartz grains, meaning the baseline model for the dry sand pack does not need to be altered. Pore space hydrate is assumed to change only the sample density and the bulk modulus of the pore fluid. The new bulk modulus was used in Gassmann's equations to establish the bulk modulus of the hydrate-saturated sample, which was then combined with the new density in Equation 1 to calculate $V_{\mathrm{p}}$. For GH084, the predicted $V_{\mathrm{p}}$ was $1080 \mathrm{~m} / \mathrm{s}$. The presence of gas hydrate in the pore space increases $V_{\mathrm{p}}$ relative to the hydrate-free, water- and gas- saturated case by only $7 \%$.

\section{Hydrate in the sediment frame}

Hydrate forming as part of the sediment frame was accounted for as though it were simply a second mineral in the quartz sand pack. Based on the hydrate saturation, a new sample porosity and density were calculated. The dry sand pack moduli in the baseline model were recalculated by replacing the moduli of quartz with the Hill average of the bulk and shear moduli for quartz and hydrate. Gassmann's equations were used to account for water and methane gas remaining in the reduced sample pore space. Placing gas hydrate in the sediment frame rather than floating freely in the pore space provided additional sample stiffness and increased $V_{\mathrm{p}}$ in sample GH084 to $1180 \mathrm{~m} / \mathrm{s}$. This is a $17 \%$ increase over the hydrate-free, water and gas-saturated case, but still only $35 \%$ of the measured wave speed.

\section{Hydrate surrounding and cementing sediment grains}

The baseline model assumes grains are held together by the effective pressure. The presence of hydrate cement dramatically increases the granular contact stiffness by locking grains in place, requiring a new mathematical description of the bulk and shear modulus for the dry baseline model (Dvorkin et al. 1994).

Bulk and shear moduli for a dry, cemented sand pack were derived from the cemented sand pack porosity, critical porosity and contact number, in addition to Poisson's ratio, bulk and shear moduli of both the quartz sand and the hydrate cement (see Table 4). A "cement arrangement" parameter was defined for the case where hydrate surrounds and cements grains. A second definition was used when hydrate formed only at the grain contacts. Gas hydrate surrounding and cementing sediment grains provided the additional sample stiffness required to increase $V_{\mathrm{p}}$ in GH084 to $3370 \mathrm{~m} / \mathrm{s}$, within the experimental uncertainty of our measured result.

\section{Hydrate forming and cementing at grain contacts}

For a given hydrate saturation, hydrate forming only at the grain contacts provides a greater increase to the sample's elastic moduli than does hydrate surrounding and cementing grains. With residual porosities below $25 \%$ however, the physical distinction between the two hydrate distributions blurs. Dvorkin et al. (1999) extended the contact cement model to low residual porosities using the formalism for hydrate growing only at grain contacts by adding hydrate cement to a two-phase system of voids and cemented sand pack at $25 \%$ porosity. For a given hydrate saturation, gas hydrate forming only at the grain contacts provided the greatest additional sample stiffness of the four distributions considered here. For sample GH084, the predicted $V_{\mathrm{p}}$ of 3865 $\mathrm{m} / \mathrm{s}$ is $15 \%$ above the measured $V_{\mathrm{p}}$ of $3360 \mathrm{~m} / \mathrm{s}$.

\section{RESULTS}

Following hydrate formation, our measured compressional wave speed, $V_{\mathrm{p}}$, in all samples was nearly three times larger than that predicted for hydrate in the pore fluid and hydrate acting as a load-bearing member of the sediment frame (Table 6). For GH084 in particular, $V_{\mathrm{p}}$ was nearly four times larger than the predicted wave speed through the initial partially saturated sand pack (Table 5). From these results we concluded that the sample stiffness imparted by our effective pressure of $250 \mathrm{kPa}$ cannot account for our measured wave speeds. Cementation of the quartz sand pack by gas hydrate is required to generate the bulk and shear moduli necessary to pass compressional waves at the measured speeds.

Of the two cementation distributions considered here, hydrate formation surrounding grains and cementing grain contacts most closely predicted our measured compressional wave speed for GH084 and GH085, which have initial water saturations of 31 and $16 \%$ of the pore space, respectively (Table 6). For GH083, with an initial water saturation of $58 \%$, the final porosity of $11 \%$ necessitated using the low-porosity, high-hydrate saturation cementation model in which hydrate surrounding grains and hydrate forming only at grain contacts are considered equivalent physical descriptions.

Hydrate surrounding grains mimics the initial water distribution. From the close fit between our measured and modeled results, we inferred that liquid water does not migrate significantly before or during hydrate synthesis. Significant water migration, leading to pooling of water at the base of a sample, could potentially shut off all but the lowest water layer from the methane

TABLE 6. Compressional wave speed comparison. Model uncertainties result from hydrate saturation uncertainties (see Table 3)

\begin{tabular}{lccr}
\hline & $\mathrm{GH} 083$ & $\mathrm{GH} 084$ & $\mathrm{GH} 085$ \\
\hline Measured & $4000(20)$ & $3360(17)$ & $3080(15)$ \\
Contact cement & $4195(20)$ & $3865(15)$ & $3810(10)$ \\
Surround and cement grains & $4195(20)$ & $3370(30)$ & $3160(20)$ \\
Load bearing & $1820(40)$ & $1180(15)$ & $1085(5)$ \\
Pore filling & $1555(25)$ & $1080(10)$ & $1030(5)$ \\
\hline
\end{tabular}

Note: Units for all values are $\mathrm{m} / \mathrm{s}$. 
gas supply. Without access to methane, water left in the overlying sample would not convert to hydrate, lowering our hydrate yield and measured cage occupancies (Table 3 ). We instead believe hydrate formation replaces liquid water surrounding sediment grains with solid hydrate, cementing adjacent grains in the process.

Cementation of quartz grains during hydrate formation also provides an explanation of our observed waveform evolution. Figure 2 shows the waveform at three stages during experiment GH084 (our midrange water-saturation sample). When the acoustic endcaps were held together in the absence of a sample, the transmitted wave form shape is similar to that observed in Figure $2 \mathrm{c}$ : the signal began with approximately $25 \mu \mathrm{s}$ of high-frequency $(\sim 600 \mathrm{kHz})$ energy followed by a tail of low-frequency $(\sim 130$ $\mathrm{kHz}$ ) energy. Because attenuation of acoustic energy increases with increasing signal frequency in unconsolidated granular material (White 1966), our sand pack acted as low-pass filter and completely attenuated our signal.

Cementation of sand grains during hydrate formation stiffens the sample. As sand grains are more tightly locked into their respective positions, the sample passes increasingly higher acoustic frequencies and allows lower frequencies to pass more efficiently. The $130 \mathrm{kHz}$ portion of the signal was measurable by the time the sample had been in the hydrate stability field for 75 hours, but the $600 \mathrm{kHz}$ energy was still too strongly attenuated to be clearly observed (Fig. 2a). The reported wave speed in this early stage of hydrate formation is likely to be lower than the true wave speed because the $600 \mathrm{kHz}$ energy defining the signal's true beginning was too strongly attenuated to produce a clear first arrival time. By 150 hours, the high-frequency component appeared and the low frequency energy continued to increase in amplitude (Fig. 2b). Both the 600 and $130 \mathrm{kHz}$ portions of the signal grew in amplitude as hydrate formation continued to cement the sand pack, reaching their peak amplitude as the wave speed stabilized (Fig. 2c). This growth pattern was observed in all three samples, but the time taken to reach the maximum wave speed increased with increasing water content. For initial water saturations of 16,31 , and $58 \%$, the wave speeds stabilized after 220,250 , and 1400 hours in the hydrate stability field respectively.

From the correspondence between measured and predicted results, we concluded that hydrate formed in our partially saturated quartz sand pack by surrounding individual quartz grains and cemented their intergranular contacts. The $V_{\mathrm{p}} / V_{\mathrm{s}}$ ratio predicted by this model, combined with our measured compressional wave speeds, gave us enough information to utilize standard rock-physics relations (Mavko et al. 1998) in estimating additional elastic parameters for our samples (Table 7).

\section{DISCUSSION}

Of the four hydrate distribution models discussed here, the model in which hydrate surrounds and cements grains most clearly predicted our measured compressional wave speeds. Cementation of sand grains during hydrate formation has also been observed in the laboratory using other formation procedures. Stoll and Bryan (1979) formed hydrate by forcing methane gas through a water-saturated Ottawa sand pack, and Stern et al. (2000) and Waite et al. (2002) formed hydrate by warming granular ice in a pressurized methane atmosphere. In these cementation examples, as with our experiment, a continuous gas phase was present during hydrate formation.

If gas is present as individual bubbles rather than as a continuous phase, Tohidi et al.'s (2001) results show hydrate forms only in the pore fluid. They predicted that cementation occurs in natural systems only if a large portion of the pore space is filled with hydrate, implying nearly all the pore water must be bound up as hydrate before cementation occurs. In contrast, Stoll and Bryan (1979) described their cemented sample by saying "hydrate occupied part of the interstices between grains [of Ottawa sand], while the balance of the pore space was filled with channels containing free gas and water." This suggests gas availability, rather than complete pore water consumption, is required for cementation.

Outside the laboratory, cementation due to hydrate formation is observed in gas-rich environments, such as in pipelines where hydrate adheres to pipeline walls and forms coherent plugs capable of supporting pressure differences in excess of $3 \mathrm{MPa}$ (Matthews et al. 2000). In water-rich marine sediment, methane recycling due to upward migration of the hydrate stability field can potentially supply the gas required for sediment cementation by gas hydrate. This mechanism has been proposed for hydrates in the Cascadia margin (Yuan et al. 1999) and at Blake Ridge (Guerin et al. 1999), but clear evidence of this hydrate formation behavior has been difficult to establish.

In the Cascadia margin, Yuan et al. (1999) inferred the presence of hydrate cementation from their Amplitude Versus Offest (AVO) analysis of the Bottom Simulating Reflector (BSR). Their modeling reproduced their measured seismic response only if they assumed hydrate cements sediment grains, increasing the shear strength above the BSR. In calculating local hydrate concentrations, however, Yuan et al. (1999) and Spence et al. (2000) assumed hydrate is pore-filling rather than cementing.

At Blake Ridge, Guerin et al. (1999) applied the same rock physics modeling used in this paper to relate compressional wave speeds from well logs to in situ hydrate concentrations measured using a pressure core sampler (PCS). They obtained the best agreement by assuming hydrate surrounds and cements sediment grains. This is the same arrangement we observed in our laboratory samples, but runs counter to the conclusions of Helgerud et al. (1999) who applied the same rock physics modeling to the same Blake Ridge site used in the Guerin et al. (1999) study. Their closest match between wave speed measurements

TABLE 7. Elastic parameters derived assuming methane hydrate surrounds and cements quartz grains

\begin{tabular}{lcccccccc}
\hline Sample & $V_{p}(\mathrm{~m} / \mathrm{s})$ & $V_{s}(\mathrm{~m} / \mathrm{s})$ & $V_{p} / V_{s}$ & $v$ & $E(\mathrm{GPa})$ & $G(\mathrm{GPa})$ & $K(\mathrm{GPa})$ & $M(\mathrm{GPa})$ \\
\hline GH083 & $4000(20)$ & $2690(10)$ & $1.488(2)$ & $0.088(2)$ & $30.4(3)$ & $13.9(1)$ & $12.3(2)$ & $30.9(3)$ \\
GH084 & $3360(17)$ & $2300(10)$ & $1.463(2)$ & $0.062(2)$ & $19.8(2)$ & $9.3(1)$ & $7.5(1)$ & $20.0(2)$ \\
GH085 & $3080(15)$ & $2120(10)$ & $1.453(1)$ & $0.050(1)$ & $16.5(2)$ & $7.8(1)$ & $6.10(1)$ & $16.5(2)$ \\
\hline
\end{tabular}

Notes: Compressional wave speed, $V_{p}$, is measured. The $V_{\mathrm{p}} V_{\mathrm{s}}$ ratio is predicted from the hydrate distribution model. Shear wave speed $\left(V_{s}\right)$, Poisson's ratio $(v)$, Young's, $(E)$, Shear $(G)$, Bulk $(K)$, and Compressional wave moduli $(M)$, are calculated from standard rock-physics relations (Mavko et al. 1998). 
from vertical seismic profiling and well-log data and independent hydrate concentration estimates from resistivity, chlorinity, and PCS measurements was obtained assuming hydrate is a loadbearing, not cementing element of the sediment matrix. AVO analysis of the BSR in this region also suggested hydrate does not exist as a cement (Ecker et al. 1998).

Ambiguous interpretations of hydrate morphology in the Cascadia margin and Blake Ridge imply the data do not clearly demonstrate the presence of hydrate-cemented sediment in the marine environment. A more definitive conclusion can be reached in the permafrost gas hydrate system, which has been studied in detail at the Mallik drill site in northern Canada. From high-resolution well logging, Lee and Collett (2001) inferred hydrate exists as a pore-filling rather than cementing phase in the sediment matrix.

The lack of clear evidence for cementation in natural hydrate deposits has implications for laboratory research of elastic parameters or transport properties controlled by the pore-scale distribution of hydrate in unconsolidated sediments. Hydrate formation in gas-rich laboratory systems can produce highpurity hydrate and reproducible samples suitable for physical property testing (Stern et al. 2000), but hydrate cementation in such systems may make it difficult to apply laboratory results to applications in marine or permafrost environments. To mimic non-cementing hydrate morphologies during laboratory measurements of physical properties in hydrate-bearing sediment may require forming hydrate in a water-rich system without an abundant free gas phase.

\section{ACKNOWLEDGMENTS}

This work was supported by the U.S. Geological Survey's Coastal and Marine Geology and Eastern Region Gas Hydrate Programs, in addition to DOE contract DE-AI21-92MC29214.

\section{REFERENCES CITED}

Collett, T.S. (2001) A review of well-log analysis techniques used to assess gashydrate-bearing reservoirs. In C.K. Paull and W.P. Dillon, Eds., Natural Gas Hydrates: Occurrence, Distribution and Detection, 124, p. 189-210. American Geophysical Union, Washington, D.C.

Dvorkin, J. and Nur, A. (1998) Acoustic signatures of patchy saturation. International Journal of Solids and Structures, 35, 4803-4810.

Dvorkin, J., Nur, A., and Yin, H. (1994) Effective properties of cemented granular material. Mechanics of Materials, 31, 461-469.

Dvorkin, J., Prasad, M., Sakai, A., and Lavoie, D. (1999) Elasticity of marine sediments; rock physics modeling. Geophysical Research Letters, 26, 1781-1784.

Dvorkin, J., Helgerud, M.B., Waite, W.F., Kirby, S.H., and Nur, A. (2000) Introduction to physical properties and elasticity models. In M.D. Max, Ed., Natural Gas Hydrate In Oceanic and Permafrost Environments, p. 245-260. Kluwer, Dordrecht, Netherlands.

Ecker, C., Dvorkin, J., and Nur, A. (1998) Sediments with gas hydrates; internal structure from seismic AVO. Geophysics, 63, 1659-1669.

Gassmann, F. (1951) Uber die elastizitat poroser medien. Vierteljarhrsschrift der Naturforschenden Geselschaft in Zurich, 96, 1-23.

Guerin, G., Goldberg, D., and Meltser, A. (1999) Characterization of in situ elastic properties of gas hydrate-bearing sediments on the Blake Ridge. Journal of Geophysical Research B, 104, 17,781-17,796.

Haq, B.U. (2000) Climatic impact of natural gas hydrate. In M.D. Max, Ed., Natural Gas Hydrate In Oceanic and Permafrost Environments, p. 137-148. Kluwer Academic Publishers, Dordrecht, Netherlands.

Helgerud, M.B. (2001) Wave speeds in gas hydrate and sediments containing gas hydrate: A laboratory and modeling study. Doctoral Thesis, Stanford University, Palo Alto, California, U.S.A.

Helgerud, M.B., Dvorkin, J., Nur, A., Sakai, A., and Collett, T.S. (1999) Elastic-wave velocity in marine sediments with gas hydrates; effective medium modeling. Geophysical Research Letters, 26, 2021-2024.
Hornbach, M.J., Holbrook, W.S., Gorman, A.R., Hackwith, K.L., Lizarralde, D., and Pecher, I. (2003) Direct seismic detection of methane hydrate on the Blake Ridge. Geophysics, 68, 92-100.

Hovland, M. and Gudmestad, O.T. (2001) Potential influence of gas hydrate on seabed installations. In C.K. Paull and W.P. Dillon, Eds., Natural Gas Hydrates: Occurrence, Distribution and Detection, 124, p. 307-315. American Geophysical Union, Washington, D.C.

Kennett, J.P., Cannariato, K.G., Hendy, I.L., and Behl, R.J. (2003) Methane hydrates in Quaternary climate change: The clathrate gun hypothesis, $216 \mathrm{p}$. American Geophysical Union, Washington, D.C.

Kvenvolden, K.A. (1993a) Gas hydrates, geological perspective and global change. Reviews of Geophysics, 31, 173-187.

_ _ - (1993b) A primer on gas hydrates. In D.G. Howell, K. Wiese, M. Fanelli, L.L. Zink, and F. Cole, Eds., U.S. Geological Survey Professional Paper, Report: P 1570, p. 279-291. U.S. Geological Survey, Reston.

Kvenvolden, K.A. and Lorenson, T.D. (2001) The global occurrence of natural gas hydrates. In C.K. Paull and W.P. Dillon, Eds., Natural Gas Hydrates: Occurrence, Distribution and Detection, 124, p. 3-18. American Geophysical Union, Washington, D.C.

Lee, M.W. and Collett, T.S. (2001) Elastic properties of gas hydrate-bearing sediments. Geophysics, 66, 763-771.

Matthews, P.N., Notz, P.K., Widener, M.W., and Prukop, G. (2000) Flow loop experiments determine hydrate plugging tendencies in the field. In G.D. Holder and P.R. Bishnoi, Eds., Gas Hydrates: Challenges for the Future, 912, p. 330-338. Annals of the New York Academy of Sciences, New York.

Mavko, G., Mukerji, T., and Dvorkin, J. (1998) The Rock Physics Handbook: Tools for Seismic Analysis in Porous Media, 329 p. Cambridge University Press, Cambridge.

McGee, T.M. and Woolsey, J.R. (2000) A remote station to monitor gas hydrate outcrops in the Gulf of Mexico. In G.D. Holder and P.R. Bishnoi, Eds., Gas Hydrates: Challenges for the Future, 912, p. 527-532. Annals of the New York Academy of Sciences, New York.

Mindlin, R.D. (1949) Compliance of elastic bodies in contact. Journal of Applied Mechanics, 16, 259-268.

Nur, A., Mavko, G., Dvorkin, J., and Galmudi, D. (1998) Critical porosity: A key to relating physical properties to porosity in rocks. The Leading Edge, $17,357-362$.

Ruppel, C.D. (2000) Thermal state of the gas hydrate reservoir. In M.D. Max, Ed., Natural Gas Hydrate In Oceanic and Permafrost Environments, p. 29-42. Kluwer Academic Publishers, Dordrecht, Netherlands.

Sloan Jr., E.D. (1998) Clathrate Hydrates of Natural Gases, 705 p. Marcel Dekker Inc., New York.

Spence, G.D., Hyndman, R.D., Chapman, N.R., Walia, R., Gettrust, J., and Edwards, R.N. (2000) North Cascadia deep sea gas hydrates. In G.D. Holder and P.R. Bishnoi, Eds., Gas Hydrates: Challenges for the Future, 912, p. 65-75. Annals of the New York Academy of Sciences, New York.

Stern, L.A., Kirby, S.H., Durham, W.B., Circone, S., and Waite, W.F. (2000) Laboratory synthesis of pure methane hydrate suitable for measurement of physical properties and decomposition behavior. In M.D. Max, Ed., Natural Gas Hydrate In Oceanic and Permafrost Environments, p. 323-348. Kluwer Academic Publishers, Dordrecht, Netherlands.

Stoll, R.D. and Bryan, G.M. (1979) Physical properties of sediments containing gas hydrates. Journal of Geophysical Research B, 84, 1629-1634.

Sychev, V.V., Vasserman, A.A., Zagoruchenko, V.A., Kozlov, A.D., Spiridonov, G.A., and Tsymarny, V.A. (1987) Thermodynamic Properties of Methane, 341 p. Hemisphere Publishing Corporation, Washington.

Tohidi, B., Anderson, R., Clennell, M.B., Burgass, R.W., and Biderkab, A.B. (2001) Visual observation of gas-hydrate formation and dissociation in synthetic porous media by means of glass micromodels. Geology, 29, 867-870.

Waite, W.F., deMartin, B.J., Kirby, S.H., Pinkston, J., and Ruppel, C.D. (2002) Thermal conductivity measurements in porous mixtures of methane hydrate and quartz sand. Geophysical Research Letters, 29, 2229. doi:10.1029/2002GL015988.

White, J.E. (1966) Static friction as a source of seismic attenuation. Geophysics, 31, 333-339.

Winters, W.J., Dillon, W.P., Pecher, I.A., and Mason, D.H. (2000) GHASTLI; determining physical properties of sediment containing natural and laboratory-formed gas hydrate. In M.D. Max, Ed., Natural Gas Hydrate In Oceanic and Permafrost Environments, p. 311-322. Kluwer Academic Publishers, Dordrecht, Netherlands.

Yuan, T., Spence, G.D., Hyndman, R.D., Minshull, T.A., and Singh, S.C. (1999) Seismic velocity studies of a gas hydrate bottom-simulating reflector on the northern Cascadia continental margin; amplitude modeling and full waveform inversion. Journal of Geophysical Research B, 104, 1179-1191.

MANUSCRIPT RECEIVED SEPTEMBER 22, 2003

MANUSCRIPT ACCEPTED FEBRUARY 2, 2004

MANUSCRIPT HANDLED BY BRYAN CHAKOUMAKOS 